This is a postprint version of the following published document:

C. Santiuste, J. Díaz-Álvarez, X. Soldani, and H. Miguélez. Modelling thermal effects in machining of carbon fiber reinforced polymer composites. In Journal of Reinforced Plastics and Composites, April 2014; vol. 33, 8: pp. 758-766. Available in http://dx.doi.org/10.1177/0731684413515956

(C) The Author(s) 2014 


\title{
Modelling thermal effects in machining of carbon fiber reinforced polymer composites
}

\author{
C Santiuste', J Díaz-Álvarez ${ }^{2}$, Soldani $^{3}$ and H. Miguélez ${ }^{3}$
}

\begin{abstract}
Machining-induced damage is commonly observed when manufacturing components based on carbon fiber reinforced polymer (CFRP) composites. Despite the importance of thermal effects in machining CFRPs, this problem has been poorly analyzed in the literature. Predictive tools are not available for thermal phenomena involved during cutting, while only few experimental studies have been found. In this paper, a three-dimensional (3D) finite element model of orthogonal machining of CFRPs including thermal effects is presented. Predicted thermal and mechanical intralaminar damage showed strong influence of fiber orientation. Thermally affected area was larger than mechanically damaged zone. This fact confirms the importance of accounting for thermal effects when modelling CFRP machining.
\end{abstract}

\section{Keywords}

Carbon fiber reinforced polymer s, machining, modelling, thermal effects

\section{Introduction}

Carbon fiber reinforced polymer (CFRPs) composites are extensively used in high responsibility applications. This family of composites is suitable for a wide range of applications in different industrial sectors due to their attractive properties: fatigue and corrosion resistance combined with light weight, high specific stiffness and strength. Although the components are usually made to the final size of the product, machining processes are needed to achieve dimensional tolerance and assembly requirements. CFRPs are vulnerable to processinginduced damage, mainly delamination, fiber pull-out, and thermal degradation. ${ }^{1}$

\footnotetext{
'Department of Continuum Media and Structural Analysis, Universidad Carlos III de Madrid, Madrid, Spain

${ }^{2}$ Department of Bioengineering and Aerospace Engineering, Universidad Carlos III de Madrid, Madrid, Spain

${ }^{3}$ Department of Mechanical Engineering, Universidad Carlos III de Madrid, Madrid, Spain
}

Corresponding author:

C Santiuste, Department of Continuum Media and Structural Analysis, Universidad Carlos III de Madrid, Madrid, Spain.

Email: csantius@ing.uc3m.es
Conventional machining operations of CFRPs, mainly trimming and drilling for subsequent joining, should be developed to be productive processes and to guarantee the quality of the component. Machining-induced defects could affect the performance of the composite component or the mechanical joint during service life. ${ }^{2-4}$ In fact a significant percentage of components rejection in aircraft manufacturing is due to machining-induced damage, mainly delamination between adjacent plies. This phenomenon has been extensively analyzed in the literature using different approaches (see for instance a recent review focusing on composite drilling ${ }^{5}$ showing some techniques developed to minimize the occurrence of delamination).

However, mechanical delamination is not the unique damage mechanism involved in composite machining. The relatively low glass transition temperature (around $180^{\circ} \mathrm{C}$ for a typical epoxy resin in CFRPs) explains the susceptibility of the composite to suffer thermal damage. ${ }^{6}$ Matrix degradation could produce delamination related with further strength reduction. On the other hand, cutting temperature affects not only the 
surface quality of the workpiece, but also influences tool wear evolution.

Despite the importance of analyzing thermal phenomena involved in machining of composites, only few authors have focused attention on this problem.

Several authors have focused in obtaining indirect information through the measurement of temperature at the cutting tool using a thermocouple. Chen ${ }^{7}$ measured temperature during drilling at the flank surface of the drill, obtaining a significant increment of temperature $\left(120-300^{\circ} \mathrm{C}\right)$ when the cutting speed increased from 40 to $200 \mathrm{~m} / \mathrm{min}$.

The temperature obtained during drilling and orbital milling of hybrid components Ti/CFRP/Al was evaluated by Brinksmeier et al. ${ }^{8}$ using a thermocouple embedded at the tool tip. Orbital drilling involved lower temperatures and better surface quality than drilling $\left(82^{\circ} \mathrm{C}\right.$ in $\mathrm{CFRP}$ with cutting speed equal to $40 \mathrm{~m} / \mathrm{min}$ ).

In the studies reported in refs. [7,8] temperature measurement has been carried out installing a thermocouple inside the tool, giving indirect information about temperature level at the workpiece. In a recent work, ${ }^{6}$ a complete experimental work involving direct temperature measurement, both at the workpiece and at the tool is reported. Milling of CFRP was conducted with carbide endmill in dry conditions. Three measurement routes were used: tool-workpiece thermocouple method, infrared thermo-graph camera for endmill surface temperature measurement and embedded K-type thermocouple in the CFRP for measurement of the temperature at machined surface layer. At cutting speed equal to $300 \mathrm{~m} / \mathrm{min}$, the temperature at $0.3 \mathrm{~mm}$ beneath the machined surface reached $104^{\circ} \mathrm{C}$, this temperature being much lower than that measured at cutting point (tool-chip contact point).

Haddad et al. ${ }^{9}$ analyzed high speed trimming of a multidirectional CFRP using unused and used burr tools. The influence of the machining parameters (feed speed, cutting speed, and cutting distance) on the cutting forces, machining temperature, and the machined surface quality was studied. Machining with unused tools resulted in recorded temperatures lower than the glass transition temperature of the composite, while the temperature was higher than this threshold when machining with used tools and SEM analysis of the machined surface showed damaged areas. Machining parameters had strong influence on the variation of the machined surface quality and the cutting forces.

In a recent work, ${ }^{10}$ an experimental study on cutting temperature in rotary ultrasonic machining of carbon fiber reinforced plastic using two measurement methods was presented: a novel method based on fiber optic sensor and a well-known technique based on thermocouples. Both methods were compared, and the relations between input variables (ultrasonic power, tool rotation speed, and feed rate) and cutting temperature were experimentally determined.

The measurement of damage is expensive and sometimes requires destructive techniques, thus it is desirable to develop simulation tools able to reproduce damage mechanisms induced during machining. Numerical models based on finite element method appear to be useful tools for thermal phenomena analysis, since they allow quantifying temperature at difficult to access zones.

As far as the bibliographic revision has been done, numerical models accounting for thermal phenomena in machining are not available. In fact, only few works deal with modelling of cutting processes in composite. These works are mostly focused on two-dimensional (2D) approaches to simulate orthogonal cutting, although recently some attempts in three-dimensional (3D) modelling have been carried out. The main advantage of $2 \mathrm{D}$ modelling relies on the reduced computational cost; however, it is not possible to reproduce out-of-plane failure mechanisms nor simulating quasiisotropic laminates. The 2D modelling has been developed by different authors, examples can be found in ${ }^{11-14}$ focusing on the influence of fiber orientation, cutting parameters, and material properties in orthogonal machining of LFRP composites. A simplified static $3 \mathrm{D}$ analysis of state of stress in the laminate in the vicinity of the cutting edge of the tool was developed in Zitoune et al. ${ }^{15}$

The validity of the hypotheses assumed in 2D approaches to CFRP composite cutting has been analyzed in refs. $[16,17]$. Out of plane failure in orthogonal cutting of composite was studied using a 3D model based on finite elements using cohesive interactions. The influence of stacking sequence on delamination was demonstrated.

Modelling of drilling processes involves elevated difficulty, because of the need of simulating drill rotation and feed movement using both damage and erosion criteria at the elements leading to high computational cost. Complete model of CFRP drilling has recently reported in Phadnis et al. ${ }^{18}$ Good agreement between measured and predicted torque and thrust force was shown. Simplified model of drilling was developed in previous work ${ }^{19}$ assuming that the drill acts like a punch that pierces through the laminate. In a recent work, a comparison between simplified and complete models of drilling has been presented showing that the simplified model slightly overestimates delamination. ${ }^{20}$

Main contributions in the field of composite machining modelling have been summarized in a recent work. ${ }^{21}$

Despite the effort recently developed in simulating composite machining, numerical model including 
thermal issues involved during cutting has not been found in the literature. The aim of this paper was to explore the ability of numerical modelling based on finite element for simulation of temperature enhancement during cutting. The model of orthogonal cutting, previously developed and validated, ${ }^{16,17}$ has been modified in order to account for thermal effects. The model is used for prediction of intralaminar damage, delamination, and also thermal damage accounted in terms of temperature level beneath the machined surface.

\section{Numerical modelling}

The numerical model was developed using the commercial finite element code ABAQUS/Explicit. A simplified process (orthogonal cutting) is reproduced. The scheme of the numerical model is shown in Figure 1 including boundary conditions and geometry and the detail of the tool/chip interface. The bottom face boundary conditions represent the clamping applied in the experiments used for validation, ${ }^{12,22}$ while the restricted longitudinal displacements $\left(\mathrm{U}_{\mathrm{x}}=0\right)$ denote that the model represents just a portion of the composite plate.

Dynamic explicit analysis was carried out including geometric non-linearity and large deformations options. The tool was meshed with 8-node brick elements with reduced integration (C3D8R in ABAQUS/ Explicit notation), and wedge elements (C3D6 in ABAQUS/Explicit notation) were used for the laminate. $^{23}$ The use of wedge elements (prismatic element with triangular section) minimizes the dependence of the results with mesh orientation in the ply plane.

A compromise between accuracy and computational cost should be achieved when selecting the element size directly involved in time step. Mesh sensibility analysis with element size was carried out for the deformable workpiece. Two different meshes were checked (element size 7 and 5 microns, respectively) leading to negligible differences when predicting cutting forces or damage. Since the computational cost was significantly increased (around 25\%) when the element size was decreased, it was stated a minimum element size around the cutting zone equal to $7 \mu \mathrm{m}$ showing reasonable accuracy and computational cost.

The tool was assumed to behave rigid. The interaction between workpiece and tool was modelled using the contact algorithm surface-node surface available in ABAQUS/Explicit.

Due to the deletion of elements during cutting process, the contact was defined between the tool surface and the composite plate nodes in the region adjacent to the contact area. In addition, a self-contact condition was used to avoid penetration between eroded composite elements.

The coefficient of friction at the tool-chip interface was varied from 0.4 to 0.8 . This value is difficult to determine, and there are only few experimental works dealing with identification of contact characteristics between composite and tool. ${ }^{24}$ The value of friction coefficient influences friction energy and thus the
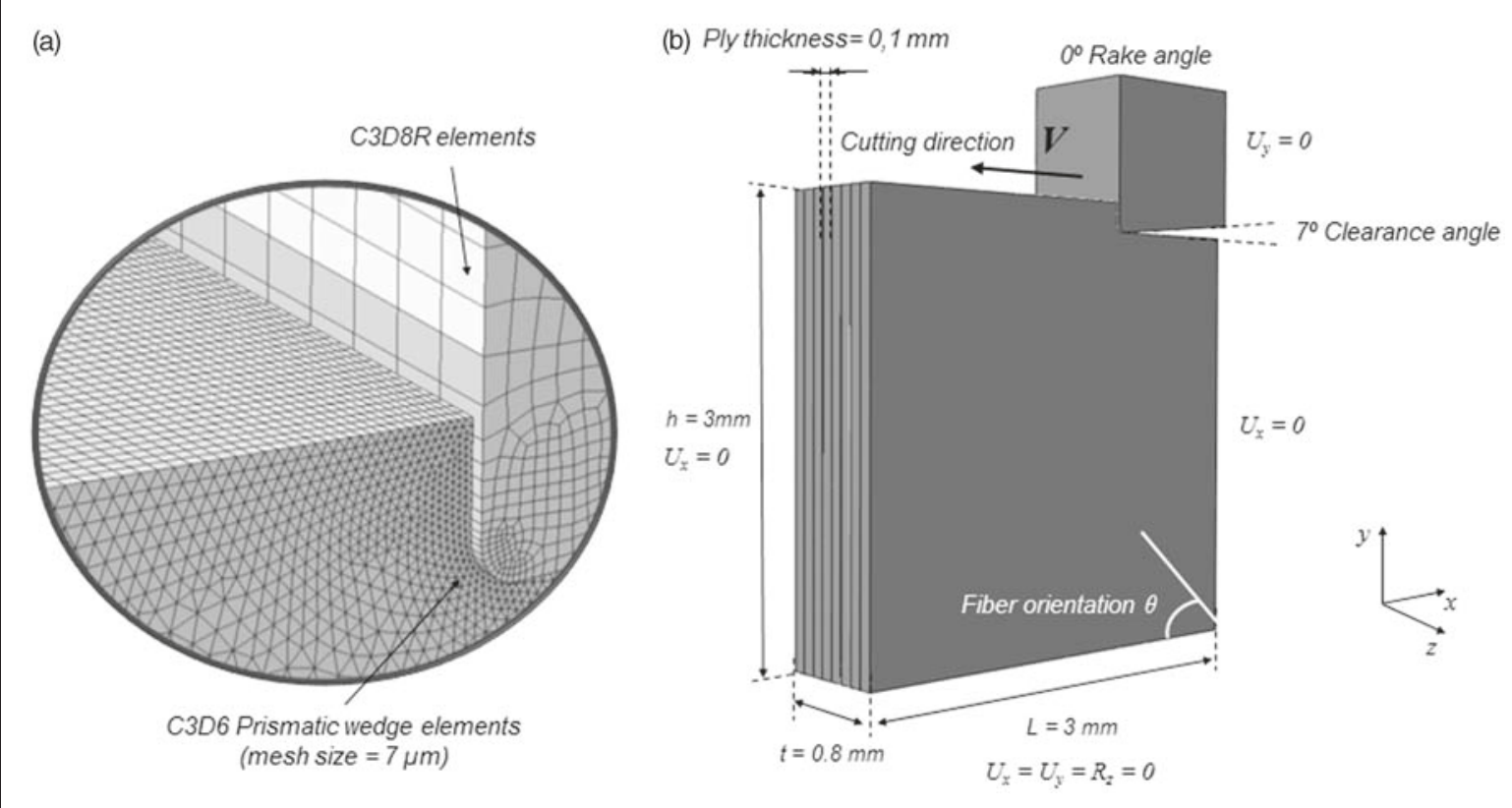

Figure I. Scheme of the numerical model for orthogonal cutting: (a) detail of the tool-chip interface and (b) boundary conditions and geometry. 
amount of heat generated at the interface. Heat partition between tool and chip was stated equal to $20-80 \%$. It is worth noting that the model does not allow to obtain thermal steady state because of the extremely elevated calculation time required. However, it is important to state in the model heat partition percentages corresponding to steady state during current industrial operations. The strong difference of temperature between tool and workpiece during steady state conditions and the common use of coating protecting tool from wear but also lowering heat transmission to the tool substrate justify the larger amount of heat transmitted to the workpiece.

The anisotropic composite was modelled with an elastic behavior up to failure. Failure was represented with Hou model ${ }^{25}$ (see Table 1).

Hou proposed the same formulation under tensile and compressive loading for fiber failure criterion, including longitudinal shear stresses $\sigma_{12}$ and $\sigma_{13}$. The transverse shear stress $\sigma_{23}$ was included for matrix cracking criterion. Parameters in Table 1 are the following: $\sigma_{11}, \sigma_{22}$, and $\sigma_{33}$ are the stresses in longitudinal, transverse, and through-the-thickness directions, respectively; $\sigma_{12}, \sigma_{23}$, and $\sigma_{13}$ are the shear stresses; $X_{T}$ and $X_{C}$ are the tensile and compressive strengths in longitudinal direction; $\mathrm{Y}_{\mathrm{T}}$ and $\mathrm{Y}_{\mathrm{C}}$ are the tensile and compressive strengths in the transverse direction; $\mathrm{S}_{\mathrm{L}}$ is the longitudinal shear strength; and $\mathrm{S}_{\mathrm{T}}$ is the transverse shear strength (failure occurs when $d_{i j}$ reaches the value 1).

Hou formulation was implemented for the threedimensional analysis through a VUMAT subroutine, developed to model the long fiber composite behavior, including a procedure to degrade material properties. Under a given load, the stresses at each integration point were computed in the user subroutine. Then, each failure criterion was calculated as a function of stresses and, if any failure mode was reached, the material properties at that point were degraded according to the failure mode. When the failure criterion was

Table I. Hou damage criteria.

\begin{tabular}{ll}
\hline Failure mode & Hou formulation \\
\hline Fiber tension & $d_{f t}^{2}=\left(\frac{\sigma_{11}}{X_{T}}\right)^{2}+\left(\frac{\sigma_{12}^{2}+\sigma_{13}^{2}}{S_{L}^{2}}\right)$ \\
Fiber compression & $d_{f c}^{2}=\left(\frac{\sigma_{11}}{X_{C}}\right)^{2}+\left(\frac{\sigma_{12}^{2}+\sigma_{13}^{2}}{S_{L}^{2}}\right)$ \\
Matrix cracking & $d_{m t}^{2}=\left(\frac{\sigma_{22}}{Y_{T}}\right)^{2}+\left(\frac{\sigma_{12}}{S_{L}}\right)^{2}+\left(\frac{\sigma_{23}}{S_{T}}\right)^{2}$ \\
Matrix crushing & $d_{m c}^{2}=\frac{1}{4}\left(\frac{-\sigma_{22}}{S_{T}}\right)^{2}+\left(\frac{Y_{c} \sigma_{22}}{4 S_{T}^{2}}\right)-\frac{\sigma_{22}}{Y_{C}}+\left(\frac{\sigma_{12}}{S_{L}}\right)^{2}$
\end{tabular}

reached, the stresses at the damaged area were reduced to reproduce the properties degradation according to the failure mode.

The reduction of elastic properties could lead to distorted elements involving numerical problems, thus the model required the use of an element erosion criterion. The stresses on a damaged element drop to values close to zero while large deformations appear. These elements do not contribute to the strength or the stiffness of the plate, but they can cause lack of convergence during simulation and instability problems. Erosion criterion based on maximum strain criteria was implemented in the VUMAT subroutine to remove the distorted elements. After each time increment, the longitudinal strains $\left(\varepsilon_{11} \varepsilon_{22}\right.$ and $\left.\varepsilon_{33}\right)$ were evaluated, and the element was removed if one of the strains reached a critical value. The strains used in the erosion criterion were $\varepsilon_{11}{ }^{\max }=0.3, \varepsilon_{22}{ }^{\max }=0.5$, and $\varepsilon_{33}{ }^{\mathrm{max}}=0.5$, high enough to prevent the deletion of elements that contribute to the strength of the plate. Thus, numerical problems were avoided, and at the same time only strongly damaged elements were deleted. These values were established from the author's expertise for similar materials in comparable applications. ${ }^{26}$ Since element deletion is controlled by the subroutine formulation, distortion control was not used.

Subrutine VUMAT included heat conduction (see thermal properties in Table 2 obtained from scientific literature). It should be noted the anisotropic nature of the workpiece, with strong differences in thermal properties between matrix and fiber, ${ }^{27}$ resulting in no uniform heat propagation depending on fiber orientation, as will be shown in next section. The heat generated due to material deformation was assumed to be negligible. It is worth noting that CFRP composites exhibit elevated elastic modulus with small deformations even when breakage is initiated. Due to this brittle behavior, heat generation produced by plastic deformation is negligible. This behavior is quite different from that observed in metal cutting with large amounts of plastic work converted into heat leading to very high temperature at the primary shear zone. Since deformation energy is neglected, the unique heat source considered in the model was friction at the interface.

Table 2. Thermal properties of composite. ${ }^{16,26}$

\begin{tabular}{ll}
\hline Workpiece (CFRP) & \\
\hline Longitudinal thermal conductivity $(\mathrm{W} / \mathrm{mK})$ & 6 \\
Transverse thermal conductivity $(\mathrm{W} / \mathrm{mK})$ & 0.5 \\
Longitudinal thermal expansion $\left(10^{-6} / \mathrm{K}\right)$ & $\mathrm{I}$ \\
Transverse thermal expansion $\left(10^{-6} / \mathrm{K}\right)$ & 26 \\
\hline
\end{tabular}


The degradation of composite properties induced by the temperature increment was not accounted. The onset of thermal damage was considered to appear when the critical temperature was reached. Some authors consider the critical level equal to the glass transition temperature (around $180^{\circ} \mathrm{C}$ for a typical epoxy $\operatorname{resin}^{5}$ ). The threshold of temperature indicative of thermal damage was assumed to be equal to $150^{\circ} \mathrm{C}$, being a temperature value between the initiation of mechanical properties degradation (around $100^{\circ} \mathrm{C}^{28}$ ) and the resin transition temperature. ${ }^{5}$

The model was validated through the comparison with experimental results provided in recent works dealing with orthogonal cutting of the carbon-epoxy LFRP composite T300/914. ${ }^{12,22}$ The validation of the model was presented in previous works of the authors. ${ }^{16,17}$

Delamination was modelled using cohesive interactions between plies able to reproduce out of plane failure. ${ }^{17}$ The cohesive interaction allows reproducing delamination propagation as a fracture mechanics phenomenon, instead of stress-based models (as it is the case of Hou criteria). The surface-based cohesive interaction available in ABAQUS was used to predict delaminated area. Delamination onset was predicted by a quadratic stress criterion considering out-of-plane stresses, equation (1).

$$
\left\{\frac{t_{n}}{t_{n}^{0}}\right\}^{2}+\left\{\frac{t_{s}}{t_{s}^{0}}\right\}^{2}+\left\{\frac{t_{t}}{t_{t}^{0}}\right\}^{2}=1
$$

where $t_{n}$ is the normal traction stress, $t_{s}$ and $t_{t}$ are the shear traction stresses, and $t_{n}{ }^{0}, t_{S}{ }^{O}$ and $t_{t}{ }^{O}$ are maximum admissible values of stresses.

Once damage initiation is reached, the definition of a damage evolution law is required. In this work, the behavior of the cohesive interaction after damage onset was defined by Benzeggagh-Kenane (BK) model. ${ }^{29} \mathrm{BK}$ model is based on the energy dissipated due to failure considering a traction-separation response according to equation (2).

$$
G_{n}^{C}+\left(G_{s}^{C}+G_{n}^{C}\right)\left(\frac{G_{S}}{G_{T}}\right)^{\eta}=G^{C}
$$

where $G_{S}=G_{s}+G_{t}$ and $G_{T}=G_{n}+G_{S}$. The variables $G_{n}, G_{s}$, and $G_{t}$ refer to the work done by the traction and its conjugate relative displacement in the normal direction, the first and the second shear directions, respectively. The quantities $G_{n}{ }^{c}, G_{s}^{c}$, and $G_{t}^{c}$ refer to the critical fracture energies required to cause failure in the normal, the first, and the second shear directions, respectively. $\eta$ is a cohesive parameter. BK model is especially useful when the critical fracture energies during deformation purely along the first and
Table 3. Material properties including matrix cohesive characteristics.

\begin{tabular}{ll}
\hline Carbon epoxy T300/9|4 & \\
\hline Longitudinal modulus, $\mathrm{E}_{\mathrm{I}}(\mathrm{GPa})$ & 136.6 \\
Transverse modulus, $\mathrm{E}_{2}(\mathrm{GPa})$ & 9.6 \\
In-plane shear modulus, $\mathrm{G}_{\mathrm{I} 2}(\mathrm{GPa})$ & 5.2 \\
Major Poisson's ratio, $v_{\mathrm{I} 2}$ & 0.29 \\
Through thickness Poisson's ratio, $v_{23}$ & 0.4 \\
Longitudinal tensile strength, $\mathrm{X}_{\mathrm{T}}(\mathrm{MPa})$ & 1500 \\
Longitudinal compressive strength, $\mathrm{X}_{\mathrm{c}}(\mathrm{MPa})$ & 900 \\
Transverse tensile strength, $\mathrm{Y}_{\mathrm{T}}(\mathrm{MPa})$ & 27 \\
Transverse compressive strength, $\mathrm{Y}_{\mathrm{c}}(\mathrm{MPa})$ & 200 \\
In-plane shear strength, $\mathrm{S}_{12}(\mathrm{MPa})$ & 80 \\
Longitudinal shear strength, $\mathrm{S}_{\mathrm{L}}(\mathrm{MPa})$ & 80 \\
Transverse shear strength, $\mathrm{S}_{\mathrm{T}}(\mathrm{MPa})$ & 60 \\
Maximum normal traction stress $\mathrm{t}_{\mathrm{n}}{ }^{0}(\mathrm{MPa})$ & 55 \\
Maximum shear traction stress $\mathrm{t}_{\mathrm{s}}{ }^{0}(\mathrm{MPa})$ & 68 \\
Maximum shear traction stress $\mathrm{t}_{\mathrm{t}}{ }^{0}(\mathrm{MPa})$ & 68 \\
Critical fracture energy in normal direction $G_{\mathrm{n}}{ }^{\mathrm{C}}\left(\mathrm{KJ} / \mathrm{m}^{2}\right)$ & 0.3 \\
Critical fracture energy in shear direction $\mathrm{G}_{\mathrm{S}}{ }^{\mathrm{C}}\left(\mathrm{KJ} / \mathrm{m}^{2}\right)$ & 2.023 \\
Critical fracture energy in shear direction $\mathrm{G}_{t}{ }^{\mathrm{C}}\left(\mathrm{KJ} / \mathrm{m}^{2}\right)$ & 2.023 \\
Matrix cohesive property parameter $\eta$ & 1.75
\end{tabular}

the second shear directions are the same, i.e. $G_{s}^{c}=G_{t}^{c}$ (see Table 3).

The 3D model was applied to simulate orthogonal cutting of quasi-isotropic laminate considering stacking sequence $[45 /-45 / 0 / 90] \mathrm{s}$. The laminate thickness was stated equal to $0.8 \mathrm{~mm}$. The validity of the selected thickness was discussed in ref. [16].

Validation was carried out comparing predictions of cutting forces and delaminated area with experimental data found in the literature. ${ }^{12,22}$ Machining parameters and geometry are identical to those used in the experiments reported in these references. Clearance and rake angles were $7^{\circ}$ and $0^{\circ}$, respectively, and nose radius was $0.05 \mathrm{~mm}$.

The validation of numerical model in terms of cutting forces and delaminated area was reported in a previous work. ${ }^{17}$ The average temperature along the cutting edge was compared with that observed in ref. [6] shown in Figure 2. Although experimental tests reported in ref. [6] focused on milling operation, cutting conditions are qualitatively comparable with the present study, and in fact good agreement between numerical and experimental results was observed. The increment of cutting speed leads to an increment in the average temperature up to a critical value. Beyond this critical value, a plateau of about $300^{\circ} \mathrm{C}$ is observed in both experimental tests and numerical simulations. 


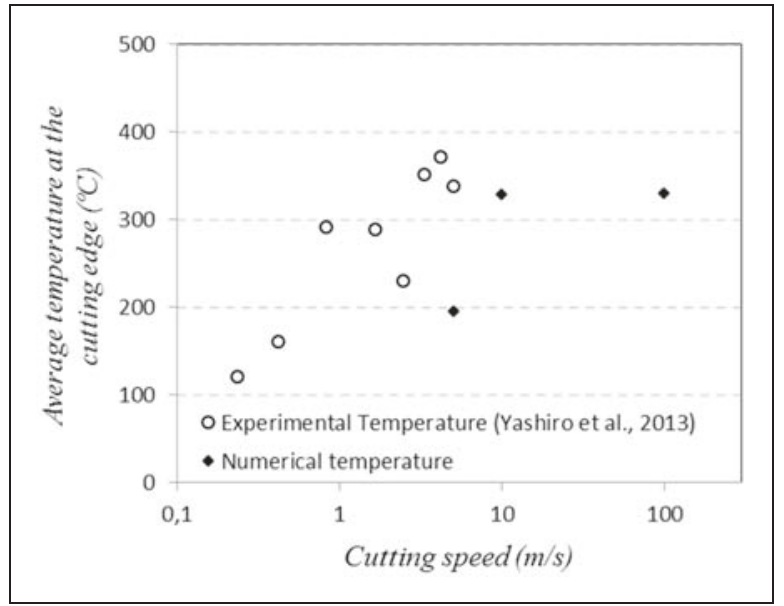

Figure 2. Average temperature on cutting edge as a function of cutting speed (log scale for cutting speed).

\section{Results and discussion}

As it has been commented previously, intralaminar damage and delamination have been analyzed in previous works of the authors. ${ }^{13,14}$ In order to analyze thermal damage, the threshold of temperature should be firstly established which represents the onset of damage. As it was commented previously, in this work the critical temperature corresponding to thermal damage was assumed to be equal to $150^{\circ} \mathrm{C}$. Figure 3 represents the predicted temperature fields at the machined surface.

It should be noted that the strong influence of fiber orientation is because of the different values of thermal conductivity of matrix and reinforcement, more elevated for the fiber. However, the influence of the orientation in the mechanical response of the ply also influences heat propagation. For instance, the depth

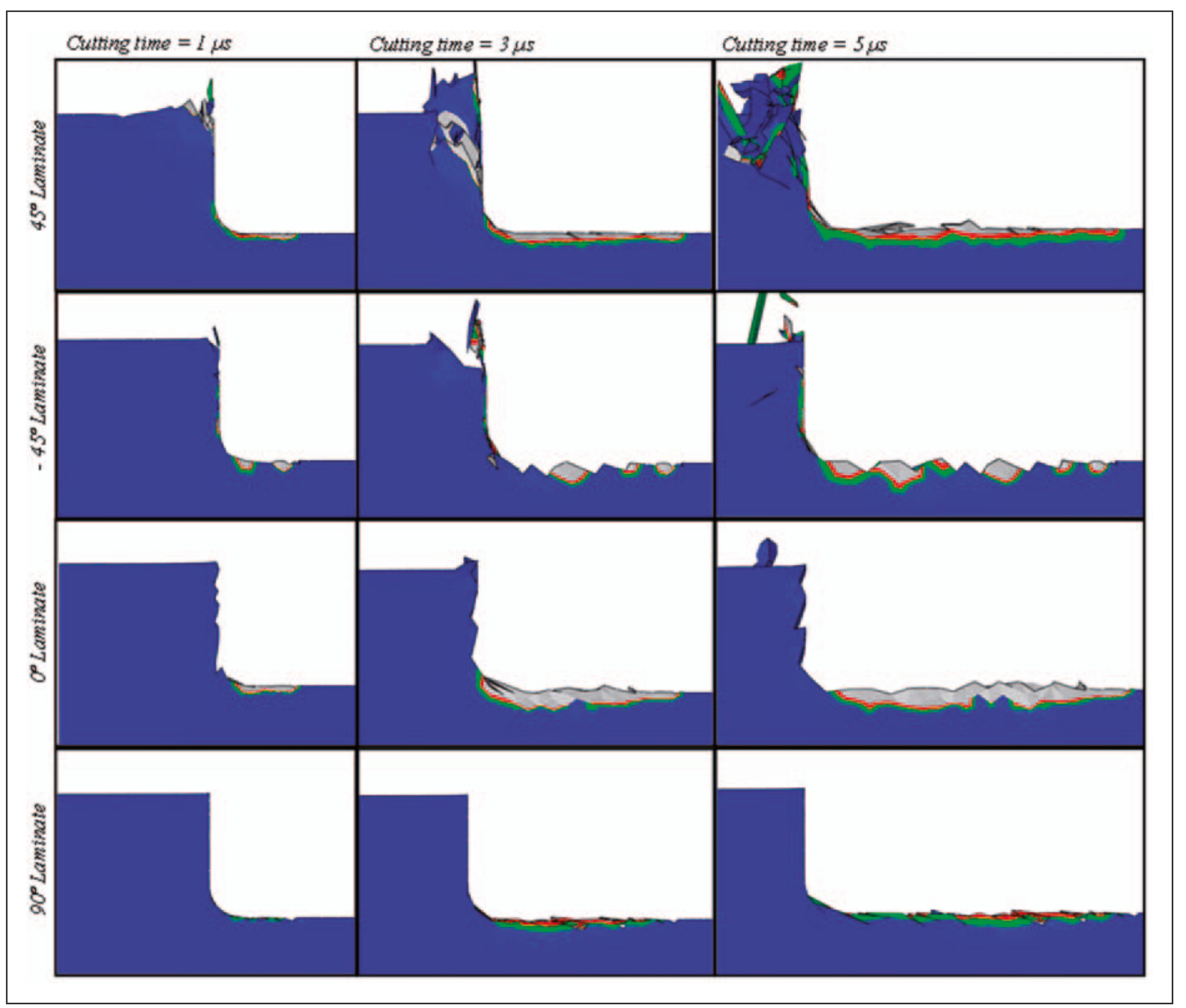

Figure 3. Temperature fields for different ply orientation $\left(90^{\circ}, 0^{\circ},-45^{\circ}, 45^{\circ}\right)$. Temperature contours range from 150 to $100^{\circ} \mathrm{C}$. Cutting speed $100 \mathrm{~m} / \mathrm{s}$, friction coefficient 0.5 . 
of the heated layer is small for fiber orientation equal to $90^{\circ}$, and this effect is due to the element erosion suffered by the layer because of mechanical damage, as it was demonstrated in ref. [11]. Damaged and subsequently eroded element does not allow heat propagation; thus thermally affected layer is reduced when compared with plies with orientation related to lower mechanical damage $\left(0^{\circ}\right.$ and $\left.\pm 45^{\circ}\right)$.

The influence of cutting speed in both thermal and mechanical damage was analyzed (see Figure 4(a) and (b)). Cutting speed was stated equal to 5, 10 and $100 \mathrm{~m} / \mathrm{s}$. Values 5 and $10 \mathrm{~m} / \mathrm{s}$ are commonly used in machining operations. The largest value, $100 \mathrm{~m} / \mathrm{s}$, is not realistic for industrial applications; however, it gives an idea of the trends for very high velocities. Both thermal and mechanical phenomena should be simultaneously analyzed because of the influence of mechanical damage leading to element deletion.

The depth beneath the machined surface of mechanically damaged zone ranges from 0 to $30 \mu \mathrm{m}$ increasing with cutting speed for orientations $0^{\circ}$ and $45^{\circ}$, while damage depth remains almost constant with speed for orientations $90^{\circ}$ and $-45^{\circ}$ (around $20 \mu \mathrm{m}$ ). The depth of thermally damaged layer (temperature higher than $150^{\circ} \mathrm{C}$ ) ranges from 10 to $45 \mu \mathrm{m}$. It is important to note the deeper penetration of thermally affected layer.

The layers corresponding to orientations $0^{\circ}$ and $45^{\circ}$ show strong increment of mechanical damage when the cutting speed increases because of the relative position between fiber and interface chip/tool. As the cutting speed rises, the pressure at the interface increases and thus the tangential force and the frictional energy enhance. The increment of tangential force is limited by the composite strength in tangential direction (as it occurs in the case of metal cutting with the limitation of thermal softening, see for instance ${ }^{30}$ ). In this case, thermal damage decreases due to the erosion induced on mechanically damaged elements.

The orientations $90^{\circ}$ and $-45^{\circ}$ are related with high levels of mechanical damage even at low velocities resulting in elements erosion, thus the mechanical damage is elevated and approximately constant with the cutting velocity. These orientations show strong increment of thermal damage when the cutting speed increases from 5 to $10 \mathrm{~m} / \mathrm{s}$; however, the damage depth remains more or less constant when the velocity is increased up to $100 \mathrm{~m} / \mathrm{s}$, because of the strong element erosion avoiding heat transmission. This trend was also observed in the milling experimental tests reported by Yashiro et al. ${ }^{6}$

The penetration beneath machined surface of thermal and mechanical affected zones as a function of friction coefficient is shown in Figure 5(a) and (b). The depth of mechanically damaged zone ranges from 5 to $35 \mu \mathrm{m}$, while the depth of thermally affected layer ranges between 10 and $45 \mu \mathrm{m}$.

When the friction increases, the amount of heat generated at the interface rises and thus it is expected the augmentation of the heated zone penetration beneath the machined surface. However, as it has been commented previously, thermal damage should be observed simultaneously with mechanical damage.

The high level of mechanical damage observed for orientations $90^{\circ}$ and $-45^{\circ}$ due to the relative position between the fibers and the tool results in thermal damage decrement for these orientations as friction coefficient increases, leading to decreased depth of the thermally affected zone. However, lower mechanical damage associated to orientations $45^{\circ}$ and $0^{\circ}$ (decreasing for orientation $0^{\circ}$ ) leads to enhanced
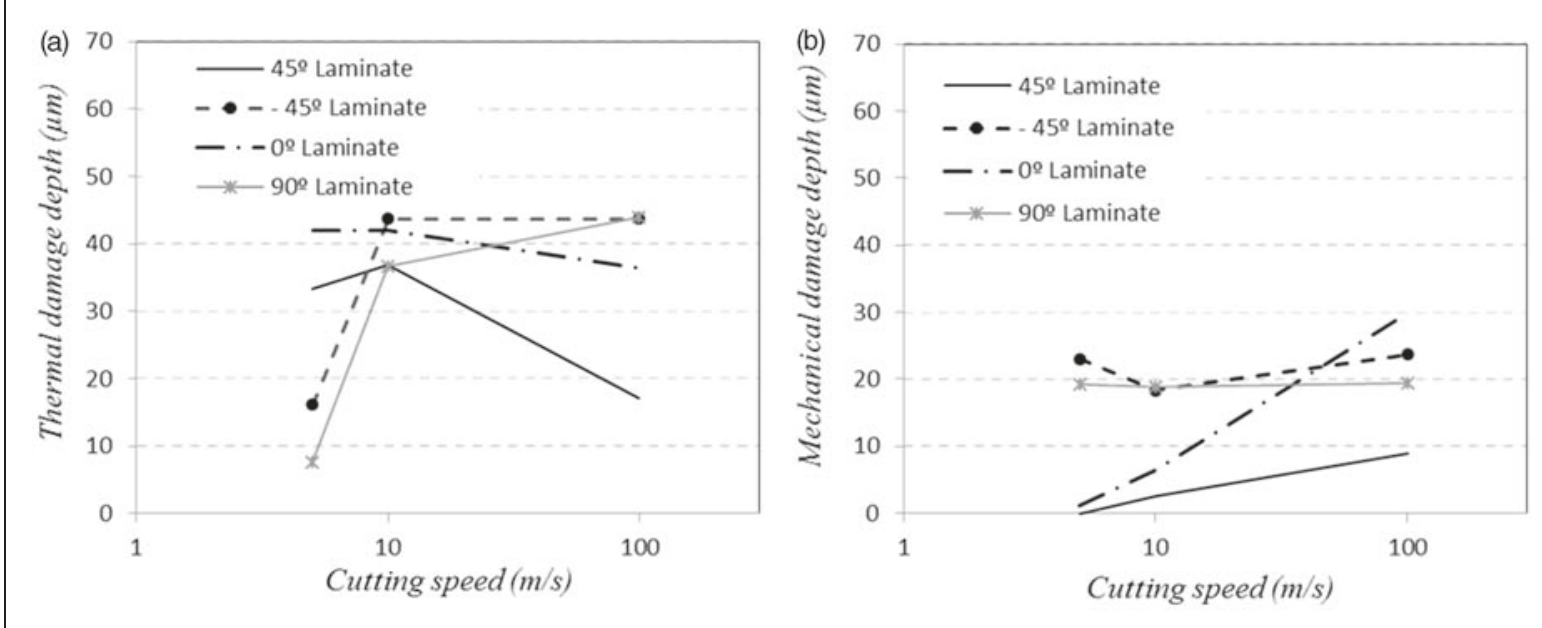

Figure 4. Evolution of thermal (a) and mechanical (b) damage depth with cutting speed (log scale for speed, friction coefficient 0.5 ). 

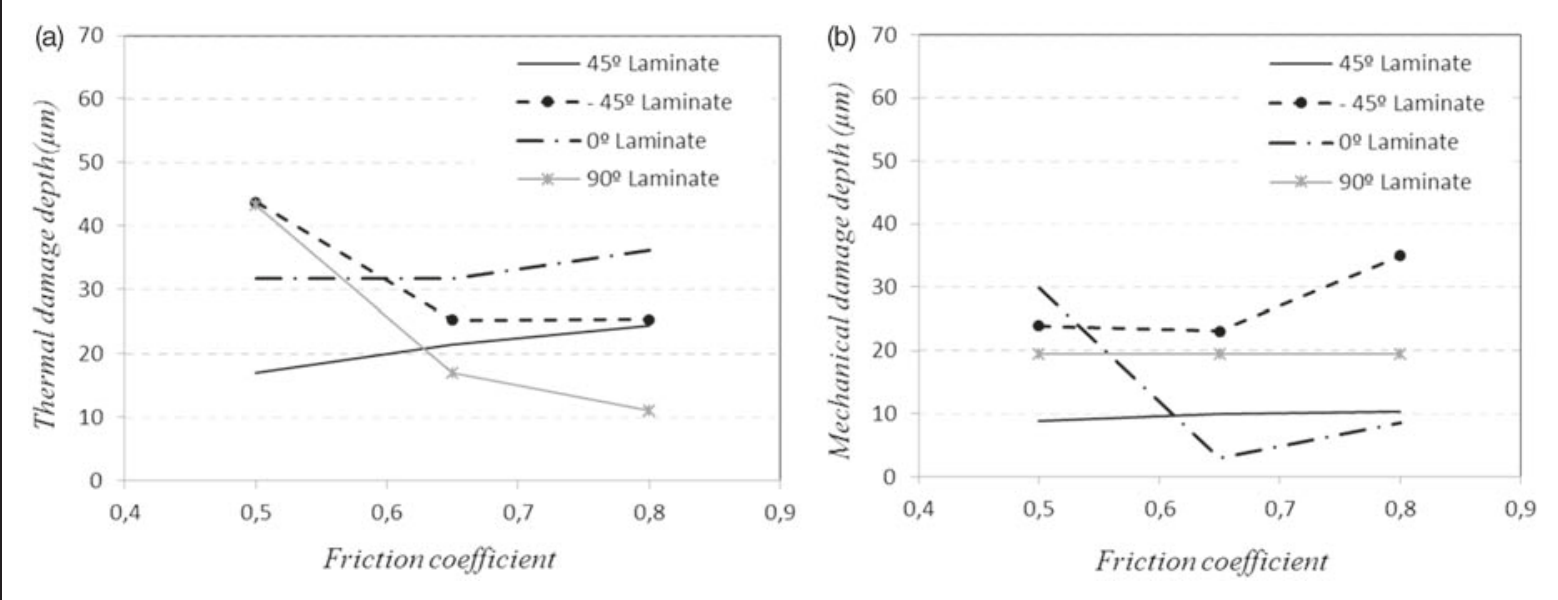

Figure 5. Evolution of thermal (a) and mechanical (b) damage depth with friction coefficient (cutting speed $100 \mathrm{~m} / \mathrm{s}$ ).

thermal damage, since frictional energy is increased and the elements are not eroded due to mechanical damage.

\section{Conclusions}

Thermal effects in orthogonal cutting of CFRP have been simulated using 3D finite element modelling. Thermal damage has been accounted in terms of the depth of the layer beneath machined surface heated up to $150^{\circ} \mathrm{C}$.

First of all, it should be noted the coupled character of the phenomena involved during machining: intralaminar damage results in properties degradation and element erosion affecting heat conduction.

Despite this limitation, interesting conclusions can be derived from this study:

- The fiber orientation strongly influences the temperature distribution because of the different values of thermal conductivity exhibited by the matrix and the fiber.

- The increment of the friction at the interface results in increased thermal damage (for orientations $0^{\circ}$ and $45^{\circ}$ ) and mechanical (for orientation $-45^{\circ}$ ). As it is well known, the friction can be reduced significantly using proper tool coating.

- The increment of cutting speed produces temperature raise; however, the increment is limited by the coupled mechanical phenomena involving element erosion and avoiding heat transmission.

- In some cases analyzed, the depth of thermally affected layer is larger than the penetration of mechanical damage. This fact indicates the importance of accounting for thermal phenomena when modelling composite cutting.
- Further analysis should include thermal damage in the failure model, since thermal effects would affect the mechanical response of the material.

\section{Acknowledgement}

The authors acknowledge the financial support for the work to the Ministry of Economy and Competitiveness of Spain under the projects DPI2011-25999 and DPI2010-15123.

\section{Funding}

This research received no specific grant from any funding agency in the public, commercial, or not-for-profit sectors.

\section{References}

1. Cong WL, Pei ZJ, Deines TW, et al. Rotary ultrasonic machining of CFRP using cold air as coolant: feasible regions. J Reinf Plastics Compos 2011; 30: 899-906.

2. Haddada M, Zitoune R, Bougherara $\mathrm{H}$, et al. Study of trimming damages of CFRP structures in function of the machining processes and their impact on the mechanical behavior. Compos Part B: Eng 2014; 57: 136-143.

3. Santiuste C, Barbero E and Miguélez MH. Computational analysis of temperature effect in composite bolted joints for aeronautical applications. J Reinf Plast Compos 2011; 30: 3-11.

4. Isbilir $\mathrm{O}$ and Ghassemieh E. Delamination and wear in drilling of carbon-fiber reinforced plastic composites using multilayer TiAlN/TiN PVD-coated tungsten carbide tools. J Reinf Plastics Compos 2012; 31: 717-727.

5. DeFu L, YongJun T and Cong WL. A review of mechanical drilling for composite laminates. Compos Struct 2012; 94: $1265-1279$.

6. Takeshi Y, Takayuki $\mathrm{O}$ and Hiroyuki S. Temperature measurement of cutting tool and machined surface layer in milling of CFRP. Int J Mach Tool Manuf 2013; 70: 63-69. 
7. Wen-Chou C. Some experimental investigations in the drilling of carbon fibre-reinforced plastic (CFRP) composite laminates. Int J Mach Tool Manuf 1997; 37: 1097-1108.

8. Brinksmeier E, Fangmann S and Rentsch R. Drilling of composites and resulting surface integrity. CIRP AnnManuf Technol 2011; 60: 57-60.

9. Haddad M, Zitoune R, Eyma F, et al. Machinability and surface quality during high speed trimming of multi directional CFRP. Int $J$ Mach Mach Mater 2013; 13: 289-310.

10. Cong WL, Zou X, Deines TW, et al. Rotary ultrasonic machining of carbon fiber reinforced plastic composites: An experimental study on cutting temperature. J Reinf Plastics Compos 2012; 31: 1516-1525.

11. Mahdi $\mathrm{M}$ and Zhang L. A finite element model for the orthogonal cutting of fibre reinforced composite materials. J Mater Process Technol 2001; 113: 373-377.

12. Iliescu D, Gehin D, Iordanoff I, et al. A discrete element method for the simulation of CFRP cutting. Compos Sci Technol 2010; 70: 73-80.

13. Santiuste C, Soldani $X$ and Miguélez H. Machining FEM model of long fibre composites for aeronautical components. Compos Struct 2010; 92: 691-698.

14. Soldani X, Santiuste C, Muñoz-Sánchez A, et al. Influence of tool geometry and numerical parameters when modelling orthogonal cutting of LFRP composites. Compos Part A-Appl Sci 2011; 42: 1205-1216.

15. Zitoune R, Collombet F, Lachaud F, et al. Experimentcalculation comparison of the cutting conditions representative of the long fiber composite drilling phase. Compos Sci Technol 2005; 65: 455-466.

16. Santiuste C, Miguélez H and Soldani X. Out-of-plane failure mechanisms in LFRP composite cutting. Compos Struct 2011; 93: 2706-2713.

17. Santiuste C, Olmedo A, Soldani X, et al. Delamination prediction in orthogonal machining of carbon long fiberreinforced polymer composites. J Reinf Plast Compos 2012; 31: 875-885.

18. Phadnis Vaibhav A, Farrukh M, Anish R, et al. Drilling in carbon/epoxy composites: Experimental investigations and finite element implementation. Compos Part A-Appl Sci 2013; 47: 41-51.

19. Durão LMP, Gonçalves DJS, Tavares JMRS, et al. Drilling tool geometry evaluation for reinforced composite laminates. Compos Struct 2010; 92: 1545-1550.

20. Feito N, López-Puente J, Santiuste C, et al. Numerical prediction of delamination in CFRP drilling. Compos Struct 2014; 108: 677-683.

21. Dandekar CR and Shin YC. Modeling of machining of composite materials: A review. Int J Mach Tool Manuf 2012; 57: 102-121.

22. Iliescu D. Approache experimentale et numerique de l'usinage a sec des composites CARBONE/EPOXY. PhD Thesis, France, 2008.

23. Hibbit K. ABAQUS user's manual 6.4-1. Pawtucket, Rhode Island, USA, Sorensen Inc., 2003.

24. Mondelin A, Furet B and Rech J. Characterisation of friction properties between a laminated carbon fibres reinforced polymer and a monocrystalline diamond under dry or lubricated conditions. Tribol Int 2010; 43: 1665-1673.

25. Hou JP, Petrinic N, Ruiz C, et al. Prediction of impact damage in composite plates. Compos Sci Technol 2000; 60: 228-273.

26. Olmedo A and Santiuste C. On the prediction of bolted single-lap composite joints. Compos Struct 2012; 94 : 2110-2117.

27. Villière M, Lecointe D, Sobotka V, et al. Experimental determination and modelling of thermal conductivity tensor of carbon/epoxy composite. Compos Part A-Appl Sci 2013; 46: 60-68.

28. Saafi M. Effect of fire on FRP reinforced concrete members. Compos Struct 2002; 58: 11-20.

29. Benzeggagh ML and Kenane M. Measurement of mixed mode delamination fracture toughness of unidirectional glass/epoxy composites with mixed mode bending apparatus. Compos Sci Technol 1996; 56: 439-449.

30. Molinari A, Cheriguene R and Miguelez H. Contact variables and thermal effects at the tool-chip interface in orthogonal cutting. Int $J$ Solid Struct 2012; 49: 3774-3796. 